\title{
O PROGRAMA FOME ZERO NOS PRONUNCIAMENTOS DOS DEPUTADOS CONSERVADORES ${ }^{1}$
}

\author{
THE FOME ZERO PROGRAMME IN THE SPEECHES \\ OF CONSERVATIVES DEPUTIES
}

Daniel de Mendonça²

\section{RESUMO}

O presente trabalho tem como objetivo principal analisar os pronunciamentos dos deputados federais do PFL, do PPB, do PTB e do PL nas sessões do Grande Expediente da Câmara Federal, no período que compreende o primeiro semestre de 2003. O objeto stricto sensu da análise são as manifestações desses parlamentares concernentes ao Programa Fome Zero, lançado em janeiro de 2003, pelo então recém-empossado presidente da República Luís Inácio Lula da Silva. Tendo como base a teoria do discurso de Ernesto Laclau e de Chantal Mouffe, este paper é resultado parcial de um esforço maior de pesquisa que visa a construir um entendimento discursivo acerca da forma como os parlamentares da direita brasileira significaram a primeira experiência de um governo de esquerda no atual contexto democrático brasileiro.

Palavras-chave: Teoria do discurso. Programa Fome Zero. Partidos de direita. Partidos conservadores.

\footnotetext{
1 Agradeço aos bolsistas de iniciação científica do Curso de Graduação em Ciências Sociais da UFPel, Felipe Corral de Freitas e Rafael Bruno Gonçalves, e à bolsista voluntária, Daiane Vilanova Antunes, pelo indispensável apoio na coleta de dados e nas discussões acerca da temática central deste trabalho.

2 Doutor em Ciência Política. Professor adjunto na Universidade Federal de Pelotas.
} 


\section{ABSTRACT}

This paper aims to analyze speeches from federal deputies of PFL, PPB, PTB and PL in the Grande Expediente sections of the Federal Chamber in the period of time which corresponds to the first semester of 2003. The stricto sensu objective of this analysis is the manifestations of these deputies concerning to Fome Zero Programme, policy released in January, 2003 by the president Luis Inácio Lula da Silva in the first moments of his government. Based on Ernesto Laclau's and Chantal Mouffe's Discourse Theory, this article is partial outcome of a research which aims mainly to construct an discursive understanding on the way that Brazilian right-wing deputies signified the first left-wing government experience in the current Brazilian democratic context.

Keywords: Discourse Theory. Fome Zero Programme. Right-Wing Parties. Conservatives Parties.

\section{INTRODUÇÃO}

O estudo da(s) ideologia(s) dos partidos conservadores no Brasil é, em nossa opinião, certamente uma das grandes lacunas da Ciência Política nacional. Por razões, quem sabe, ideológicas ou mesmo simplesmente por desinteresse dos pesquisadores brasileiros, esses partidos têm recebido pouca atenção em análises mais aprofundadas no que diz respeito à compreensão de suas concepções de mundo.

Contrastando com esta pequena produção científica, ainda mais se comparada com o volume de estudos sobre os partidos de esquerda, ${ }^{3}$ os partidos conservadores têm influenciado sobremaneira o atual sistema político brasileiro, elegendo bancadas expressivas em nível federal e participando ativamente de todos os governos democráticos desde 1985. Nesse sentido, formaram coalizões com partidos de centro, ${ }^{4}$ alternadamente ou mesmo conjuntamente com PMDB e PSDB, para as composições políticas dos governos Tancredo Neves/José Sarney (1985-1990), Fernando Collor de Melo/Itamar Franco (1990-1994) e nos dois períodos do presidente Fernando Henrique Cardoso (entre 1995 e 2002).

Com a vitória eleitoral de Luís Inácio Lula da Silva, poder-se-ia imaginar um desfecho a este cenário, no sentido de, pelo menos grosso modo, não seria um completo absurdo

\footnotetext{
3 Entretanto, um estudo interessante e comparativo sobre a ideologia e a composição social dos principais partidos políticos brasileiros de centro, de esquerda e de direita é o desenvolvido por Rodrigues (2002a).

4 Existe uma série de estudos que constroem tipologias do sistema partidário brasileiro. Nesses trabalhos, existem divergências entre os autores no que tange, entendemos, pequenos ajustes de localização dos partidos entre posições de esquerda, de direita e de centro. Para fins deste artigo, concordamos com a análise de Rodrigues com relação aos principais partidos no período da presente análise, considerando o fato de que suas nomenclaturas sofreram alterações posteriormente. Assim, segundo Rodrigues (2002b, p. 48), "pelo critério adotado, resultaram três blocos ideológicos formados por três pares de partidos. No bloco da direita, o PPB e o PFL; no do centro, o PMDB e o PSDB e, no da esquerda, o PDT e o PT. Essa classificação ideológica é predominante entre os cientistas políticos brasileiros e estrangeiros e corresponde àquela veiculada pelos meios de comunicação. Não interessa aqui discutir o significado "intrínseco" e a correção "científica" dessa classificação. Para os fins deste trabalho, limito-me a acompanhar as avaliações expressas pela maior parte dos especialistas, meios de comunicação e pelos eleitores mais informados".
} 
esperar, a partir de 2003, uma aliança de centro-esquerda e uma nova realidade governativa, a qual finalmente relegaria os partidos conservadores à condição de oposição (como ocorreu no caso dos partidos de esquerda entre 1985 e 2002). Entretanto, de fato, isto não aconteceu, tendo em vista que alguns destes partidos, nomeadamente o PL e o PTB, compuseram o governo Lula desde os primeiros minutos de seu mandato. Aliás, os indícios de que este padrão de participação dos partidos conservadores se manteria, mesmo em um governo de esquerda, já estavam presentes antes mesmo da eleição de Lula.

Nesse sentido, já na aliança eleitoral de primeiro turno, o principal partido de oposição do Brasil, o Partido dos Trabalhadores, selou aliança com um partido pouco expressivo da direita brasileira, o Partido Liberal, dando a entender que a sua já tradicional Frente Popular, constituída tão-somente por agremiações políticas de esquerda, não era suficiente para vencer as eleições à Presidência da República. Este ato, mais simbólico do que propriamente levando-se em consideração a força política do $\mathrm{PL}$, sinalizava certamente uma tendência de que o governo do PT abriria sua coalizão para um rol de partidos e de ideologias políticas para além de uma mera frente de centro-esquerda. Dessa forma, o PT não abriu mão da possibilidade de compor politicamente com a direita brasileira.

Duas explicações parecem justificar essa ação tomada pelo governo Lula. A primeira delas se dá pela própria lógica do sistema político-partidário brasileiro, composto por uma miríade de siglas, as quais, unitariamente, ficam muito aquém de compor uma maioria parlamentar indispensável para levar a efeito projetos estruturais de governo. No Brasil, é notório que um governante que queira efetivamente governar necessita formar coalizões para tal fim. Uma característica, portanto, do nosso sistema político é a constante necessidade de composição. Nesse sentido, é muito difícil rejeitar alianças e até mesmo deixar de buscá-las.

A segunda explicação para a participação de partidos de direita no governo Lula foi a imediata postura de oposição a que se colocaram o PSDB e o PFL. Ambos os partidos, que comumente elegem expressivas bancadas, já autolocalizados no bloco oposicionista, obrigaram uma postura ainda mais agressiva do governo na busca de sua base de sustentação. Somando-se a isso, o PT tinha ainda de lidar com uma difícil composição com o PMDB, partido que comumente apresenta baixa coesão interna, sobretudo tendo em vista os diferentes projetos políticos de suas principais lideranças. Assim, logo no início do seu mandato, o PT recebeu, como já fizemos menção, oficialmente a adesão, além do já coligado PL, do PTB. ${ }^{5}$

Tendo em vista o rápido retrospecto acima apresentado, que se constituiu no esforço inicial do governo Lula de formar sua base de sustentação, o presente trabalho tem como objetivo principal analisar os pronunciamentos dos deputados federais do PFL, do PPB, do PTB e do PL, nas sessões do Grande Expediente da Câmara Federal, no período que compreende o primeiro semestre de 2003. Assim, o principal interesse neste artigo é o de analisar os discursos dos parlamentares dos partidos acima nominados, buscando evidenciar a forma como os mesmos significaram o Programa Fome Zero, lançado pelo governo federal em janeiro de 2003.

5 O PTB apoiou a candidatura Lula já no segundo turno da campanha eleitoral de 2002. 
A razão da escolha do Grande Expediente fundamenta-se no fato de que este é o momento em que os deputados apresentam, de forma mais detalhada, pelo tempo que dispõem na tribuna, seus posicionamentos acerca das discussões políticas nacionais que estão na pauta do dia. Acreditamos, por isso, que este é um momento privilegiado em que são apresentadas suas concepções ideológicas de mundo, suas posições em relação à forma como o Executivo conduz suas ações de governo e, sobretudo, como esses parlamentares se posicionam em torno dos grandes temas nacionais.

Já a temática do Fome Zero foi escolhida tendo em vista que o referido Programa teve seu momento de maior debate parlamentar justamente no primeiro semestre de 2003, sobretudo, entre os meses de fevereiro e junho. Tais debates, no âmbito do Legislativo, tiveram efeito pelo fato de que este tema foi um dos principais lançados pelo governo Lula no período inicial do seu primeiro mandato.

\section{ASPECTOS METODOLÓGICOS}

O presente trabalho é parte de uma pesquisa mais ampla que tem como objetivo principal compreender o comportamento discursivo dos quatro principais partidos conservadores do Brasil (PFL, PPB, PTB e PL). Tomamos a caracterização dos partidos conservadores, ou de direita, tendo em vista o trabalho de Mainwaring, Meneguello e Power (2000), os quais caracterizam tais partidos a partir de critérios programáticos entendidos como conservadores ou de direita. É digno de nota que esses autores não diferenciam substancialmente "partidos conservadores" de "partidos de direita", sendo que tal diferenciação não será aqui também relevante.

As questões mais gerais que norteiam o esforço geral de pesquisa acima destacado são as seguintes: como os parlamentares dos quatro maiores partidos brasileiros de direita significaram as ações políticas empreendidas pelo primeiro governo Lula? Quais foram as leituras que a direita fez de um governo de esquerda? Para responder a tais questões de ordem geral, portanto, escolhemos como estratégia a análise dos discursos relativamente ao que diz respeito à reação dos parlamentares com respeito às políticas empreendidas pelo governo federal. Neste trabalho, a política escolhida é a do Programa Fome Zero (PFZ) e, nesse sentido, especificamente, questionamos: como os parlamentares conservadores do PFL, do PPB, do PTB e do PL posicionaram-se com relação ao PFZ?

Para a resposta desta questão central, tomamos os procedimentos metodológicos a seguir descritos. Tendo como metodologia principal a análise de discursos, inicialmente foram recolhidos todos os pronunciamentos, oriundos das sessões do Grande Expediente da Câmara Federal, dos parlamentares dos partidos supracitados no primeiro semestre de 2003. Após o recolhimento deste material, foi feito um segundo recorte, ou seja, foram descartados todos os pronunciamentos em que esses deputados não fizeram qualquer referência ao governo federal, ao presidente Lula ou mesmo ao Partido dos Trabalhadores como principal partido de sustentação política do governo. O material que faz referência ao governo constitui-se, desta forma, em nosso corpus discursivo.

O corpus discursivo foi classificado por temáticas a partir de fichas confeccionadas que continham, para cada pronunciamento lido, as seguintes informações: 1) Nome do 
deputado, partido e Estado de origem; 2) Data e página(s) da publicação do pronunciamento no Diário da Câmara dos Deputados; 3) Assunto geral; 4) Assuntos específicos; 5) Referências ao governo federal e; 6) Posição política assumida pelo parlamentar.

Os dois primeiros campos preenchidos não requerem qualquer informação adicional, tendo em vista serem exclusivamente informativos. Com relação aos demais, alguns comentários se fazem necessários. Dessa forma, com relação ao assunto geral, este se refere à principal questão abordada pelo parlamentar ao longo do seu pronunciamento, ou seja, o objetivo central desse pronunciamento. Entretanto, em um mesmo pronunciamento, outros assuntos podem advir o que, na maior parte das vezes, ocorre com frequência. Dessa forma, sentimos a necessidade de criar um campo para assuntos específicos, os quais acabam figurando como parte da estratégia retórica do parlamentar. Por exemplo, um deputado apresenta como assunto geral a questão dos eventuais entraves ao desenvolvimento socioeconômico no Brasil e menciona, como assunto específico, o Programa Fome Zero. Fazemos questão de ressaltar esse aspecto no sentido de demonstrar que determinados pronunciamentos que mencionam o PFZ, mencionam-no tanto como assunto geral como assunto específico.

As referências ao governo federal, dispostas no campo cinco do formulário de coleta de pronunciamentos, dizem respeito às próprias menções que os deputados fazem ao governo. Tais menções aparecem de várias formas, sejam como referências diretas ao presidente, às suas políticas específicas, ao Estado brasileiro confundido com o próprio governo, sejam ao Partido dos Trabalhadores. Contudo, as referências em relação ao PT somente são levadas em consideração para a análise, se as mesmas fizerem menção ao partido como entidade política constituinte do governo. $O$ último campo da ficha refere-se à posição política que o parlamentar assumiu com referência ao governo federal em torno estritamente do assunto abordado em seu pronunciamento. Nesse sentido, consideramos três possibilidades de posições assumidas em cada fala: favorável, contrária ou dúbia, esta última refletindo a impossibilidade de situar o pronunciamento favoravel ou contrariamente à determinada política do governo Lula.

Recolhidos todos os pronunciamentos, tendo em vista os critérios acima explicitados, para os fins específicos da elaboração deste artigo, foi realizado novamente um novo recorte. Dessa forma, foram separados do contexto dos demais pronunciamentos todos aqueles que têm, ou como assunto geral, ou como assunto específico, a temática do Programa Fome Zero.

Na etapa seguinte, passamos finalmente à análise. Assim, os pronunciamentos foram lidos pelo grupo e separados em duas posições discursivas gerais e antagônicas: uma formada pelos deputados defensores do PFZ e a outra constituída pelos pronunciamentos contrários ao Programa. Tal divisão discursiva tem por base a teoria do discurso de Ernesto Laclau e Chantal Mouffe (1985), para a qual todo discurso se constitui, inevitavelmente, a partir da existência de outro discurso antagônico. Cada um dos discursos antagônicos constitui um tipo de articulação, ou seja, uma série de sentidos que são unidos por um ponto nodal, ou seja, um ponto discursivo privilegiado que exerce uma função de representação. No caso específico deste artigo, os dois pontos nodais em questão são, respectivamente, os sentidos contrários ou favoráveis ao PFZ, que articulam uma série de outros sentidos que acompanham esses dois principais. 
Outro elemento fundamental para a presente análise diz respeito à questão da recorrência discursiva. Dessa forma, para que possamos considerar um determinado sentido efetivamente como pertencente a determinado discurso, ele deve ter sido recorrentemente produzido. Não basta que algo seja pronunciado uma vez para que se torne parte de um discurso. É necessário que tal sentido seja produzido recorrentemente para que se efetive um discurso, a partir do que Foucault (1997) e Laclau e Mouffe (1985) chamam de regularidade na dispersão. Isso se faz profundamente necessário, tendo em vista que um discurso apresenta uma determinada visão de mundo (ideologia) que somente pode ser percebida tendo em vista a recorrência com que esta aparece no corpus discursivo recortado para os fins específicos de cada pesquisa.

Uma última consideração de natureza metodológica faz-se importante. Diz respeito à forma como os pronunciamentos foram categorizados como contrários ou favoráveis ao PFZ. Tal divisão não pôde ser efetivada tendo em vista unicamente critérios partidários, pois foi possível perceber reações favoráveis ao Programa, por exemplo, oriundas de deputados do PFL, principal partido oposicionista de direita. Da mesma forma, notou-se a existência de pronunciamentos contrários ao PFZ provindos de parlamentares de partidos como o PTB e o PL que formam, desde o início, a base de sustentação do governo Lula. Nesse sentido, se a divisão fosse feita simplesmente estabelecendo o corte discursivo a partir de partidos pró ou contra o governo Lula, estaríamos simplificando e essencializando uma análise que é muito mais rica e complexa, tendo em vista o fato de que discursos nunca podem ser vistos como totalidades homogêneas e coerentes, mas como estruturas marcadas por contradições e tensões internas.

\section{O DISCURSO CONTRÁRIO AO PROGRAMA FOME ZERO}

Antes de propriamente analisarmos os discursos, contrário e favorável, com relação ao Programa Fome Zero, cabe uma rápida caracterização desta política pública. Assim, o Programa constitui-se num conjunto de ações promovidas, principalmente pelo governo federal, desde o início do primeiro mandato do presidente Lula. O PFZ foi oficialmente lançado no final de janeiro de 2003 e tem como objetivo principal assegurar o acesso ao alimento àquelas pessoas que, sem a ajuda do Programa, são incapazes de obtê-lo. Além disso, segundo o governo, o PFZ tem o objetivo de incluir socialmente as populações mais carentes do Brasil, seja a partir da promoção da segurança alimentar, seja a partir de políticas públicas que promovam o acesso à educação, saúde, emprego e renda. ${ }^{6}$ Para tanto, a estratégia de ação governamental envolve, atualmente, uma série de ministérios, como o Ministério do Desenvolvimento Social e Combate à Fome, o Ministério do Desenvolvimento Agrário, o Ministério da Saúde, o Ministério da Educação, o Ministério da Agricultura, Pecuária e Abastecimento, o Ministério do Trabalho e Emprego, o Ministério da Ciência e

\footnotetext{
${ }^{6}$ Essa posição é claramente apontada por Patrus Ananias (2004, p. 2): "Coube, entretanto, ao Governo do presidente Luiz Inácio Lula da Silva alçar a erradicação da fome e da exclusão social à condição de questão política central. Isto é: eliminar a fome e resgatar a cidadania a milhões de brasileiros são passos fundamentais para a consecução de um projeto de Nação em que cada cidadão tenha a oportunidade de realizar plenamente suas potencialidades. O "Fome Zero" é a política pública que expressa esta prioridade governamental e a compartilha com a sociedade, mobilizando-a através de ações e parcerias. Os objetivos e métodos do Fome Zero não são assistencialistas. Ao contrário: visam à universalização dos direitos da cidadania, a começar pelos direitos sociais básicos: acesso à alimentação, saúde e educação".
} 
Tecnologia, o Ministério da Integração Nacional, o Ministério do Meio Ambiente, o Ministério da Justiça e da Secretaria Especial de Políticas de Promoção da Igualdade Racial e o Ministério da Fazenda. ${ }^{7}$ A partir do lançamento do Programa, uma série de estudos dedicaram-se a analisar suas repercussões sociais. Neste artigo, contudo, não pretendemos fazer uma incursão em tais análises, o que fugiria dos nossos objetivos analíticos. ${ }^{8}$

O discurso contrário ao Programa Fome Zero, para fins específicos deste artigo, será analisado tão-somente tendo em vista os pronunciamentos dos parlamentares que se posicionaram negativamente em relação a tal política promovida pelo governo federal, ficando excluídos quaisquer outros argumentos produzidos exteriormente à Câmara dos Deputados. Nesse ponto, é necessário apontar uma observação inicial. Em nenhum momento, qualquer parlamentar posicionou-se contrariamente ao "combate à fome" em si, tendo em vista que o mesmo deve ser diferenciado do PFZ. Assim, além de ser um ato de profunda desumanidade, certamente constituir-se-ia num grave erro político posicionar-se contra o mérito do Programa, ou seja, o combate à fome. Dessa forma, a estratégia retórica dos parlamentares conservadores, sobretudo os do PFL, concentrou-se na crítica ao Programa como política pública, seja no aspecto condizente à sua concepção, seja na sua forma mesma de execução.

No que tange à concepção do PFZ, o ponto de crítica mais importante diz respeito ao sentido, produzido pelos parlamentares, de que o Programa seria meramente assistencialista. Neste particular, o Programa é significado como uma simples política de distribuição de alimentos às pessoas que passam fome em regiões carentes do Brasil, sem qualquer acompanhamento de demais políticas públicas em direção ao reconhecimento e à inclusão destas pessoas. Pelo contrário: segundo o discurso contrário ao PFZ, tais políticas do governo federal existiriam justamente para perpetuar a pobreza e a relação de dependência dessas populações em relação ao governo. Tomemos parte do pronunciamento da deputada federal Edna Macedo (PTB-SP), que sugere a natureza assistencialista do Programa:

E, apesar de elogiarmos o programa de combate à fome do atual Governo, nós o encaramos como algo emergencial, pois, da forma como ele está sendo conduzido até agora, não restaura, em absoluto, a dignidade dessas vítimas do desgoverno. Muito pelo contrário. Se nada for feito para dar a esses brasileiros emprego e salário digno, capaz de mantê-los e as suas famílias, vamos apenas transformá-los em mendigos, oficializados em sua condição pelas autoridades de que ficarão dependentes para não morrerem de fome, o que é perigoso e imoral. 0 país tem de contar com políticas desenvolvimentistas e sociais consistentes. Não queremos regimes paternalistas (Diário da Câmara dos Deputados, 29/04/2003, p. 17161).

\footnotetext{
7 As informações gerais sobre o Programa Fome Zero estão dispostas no site oficial do Programa (http:// www.fomezero.gov.br).

8 Cabe mencionar, contudo, algumas análises interessantes que se detiveram ao estudo do Fome Zero. Nesse sentido, para uma caracterização do Programa, sugerimos a leitura de Silva, Belik e Takagi (2001) e Belik e Del Grossi (2003). Para uma análise crítica, veja Yasbek (2004).
} 
A primeira observação que merece destaque no excerto acima se refere ao partido político ao qual a deputada está filiada, o PTB, que compõe a base de sustentação do governo federal. Notemos que o tom inicial de sua fala indica um "elogio" ao "programa de combate à fome do atual governo". Contudo, tal elogio é apenas um detalhe no contexto do seu pronunciamento. Pelo que foi afirmado, fica clara a sua posição acerca do PFZ. Para a parlamentar, o Programa é, na terminologia empregada neste artigo, assistencialista. Tal evidência pode ser percebida na constatação de que o Fome Zero é "algo emergencial", uma vez que ele não é capaz de alçar às pessoas, de que dele necessitam, à condição de dignidade. Tal condição só será alcançada através da maior oferta de emprego e salário digno. Vemos claramente que a deputada tem a ideia de que o PFZ tem seu objetivo final restrito à distribuição de alimentos, independente da publicidade governamental que busca dar ares mais estruturais a esta política pública. É a partir dessa crença assistencialista no Programa que Edna Macedo entende a necessidade de o país "contar com políticas desenvolvimentistas e sociais consistentes". Em sua percepção, o Programa, entendido como simples distribuição de alimentos, é uma política "paternalista" e, como tal, deve ser evitada, uma vez que "oficializa" uma condição de mendicância de seus beneficiados, o que é "perigoso e imoral".

O excerto acima analisado exemplifica o ponto nodal ${ }^{9}$ do discurso contrário ao PFZ. Nesse sentido, é produzido o sentido de que o Programa tem um caráter meramente assistencialista, entendido aqui como uma ação que não visa resolver um problema congênito, como a fome, a partir de medidas estruturais de reconhecimento e de inclusão, mas tão-somente amenizar a situação miserável dos seus beneficiados. É interessante aqui destacar que esse discurso contrário às medidas meramente assistencialistas, realizadas historicamente no Brasil, tem sido comumente produzido justamente pelo campo da esquerda contra as políticas governamentais empreendidas pela direita. É possível, talvez, ampliar esse tipo de argumentação e colocá-la não propriamente como tendo um locus discursivo na esquerda necessariamente, mas como um típico discurso oposicionista, já que, pela primeira vez na história republicana recente brasileira a esquerda é efetivamente governo e a direita exerce o papel de oposição. ${ }^{10}$

Aliás, outro elemento que pode ter gerado a percepção meramente assistencialista dos opositores do PFZ é a própria denominação do programa. Apesar de, inequivocamente, "Programa Fome Zero" ser uma denominação que busca gerar um impacto publicitário, no sentido de que tem como ponto nodal a erradicação da situação de fome por que passam milhões de brasileiros, este não faz menção ao desenvolvimento econômico de regiões ou mesmo a inclusão de seus beneficiados à condição de cidadania. PFZ pode sugerir exatamente o contrário: uma política meramente assistencialista de distribuição de alimentos sem o acompanhamento de qualquer política adicional de reconhecimento e de inclusão social.

Diretamente ligadas à crítica em relação ao caráter assistencialista do PFZ, os parlamentares sugerem as soluções ou medidas que deveriam ser tomadas pelo governo federal

\footnotetext{
9 Ponto nodal, na concepção da teoria do discurso de Laclau e Mouffe (1985), deve ser entendido como um ponto discursivo privilegiado, que representa o sentido principal de uma articulação discursiva. No contexto deste artigo, o ponto nodal do discurso contrário ao Programa Fome Zero é o sentido de que o mesmo é tão-somente uma política "assistencialista".

${ }^{10}$ Este argumento será mais bem desenvolvido na última seção deste artigo.
} 
para que uma política de erradicação da pobreza obtivesse êxito. Nesse ponto, não há propriamente um consenso sobre quais seriam as melhores ações, tendo em vista que elas são sugeridas sem o acompanhamento de um plano objetivo de execução. Apesar da referida falta e consenso sobre o que fazer, os parlamentares apontam genericamente a necessidade de "desenvolver o país", sendo o desenvolvimento visto a partir de múltiplas formas. Assim, há sugestões de incentivar a produção para aumentar a riqueza nacional e, com isso, diminuir a fome dos brasileiros. Há aqueles que afirmam a necessidade de articular o combate à fome com as condições de produção, assim como àqueles que inferem a necessidade de que haja maior oferta de emprego no país. Notemos que todas essas "soluções" são, na verdade, dotadas de uma generalidade que qualquer tipo de oposição a qualquer tipo de governo poderia enunciar.

O que talvez una todas essas "propostas" genéricas é a ideia de que seria preciso que o governo federal pensasse alternativas para impulsionar o desenvolvimento econômico do Brasil, como se isso, por si só, resolvesse o problema da fome. $O$ deputado Rogério Nunes (PFL-BA) exemplifica tal necessidade:

É necessário que o Governo do Presidente Lula, tão empenhado no combate à fome, tome consciência de que dar condições de produzir, de contribuir para a formação da riqueza nacional é tão ou até mais importante e efetivo do que dar alimento para matar a fome de agora, sem previsão para a de amanhã. [...] É melhor ensinar a pescar do que dar o peixe a quem tem fome, diz o velho ditado. Para isso, [...] é fundamental ter onde pescar (Diário da Câmara dos Deputados, 26/02/2003, p. 04221).

Tendo em vista a ideia assistencialista que tem o deputado sobre o PFZ, quando o mesmo menciona que o governo tem a intenção de somente "dar alimento para matar a fome de agora, sem previsão para a de amanhã", o parlamentar induz à ideia de que preocupações com as condições de produção e de formação da riqueza nacional são até mais importantes do que a simples distribuição de alimentos. O que chama a atenção é o fato de que não está claramente definida a melhor política de desenvolvimento econômico que poderá auxiliar na erradicação da pobreza; existe, como dissemos, uma ideia genérica e muito inspirada numa ideologia liberal, de que o simples crescimento econômico gerará políticas de maior inclusão dos desfavorecidos.

A questão do desenvolvimento da agricultura no país pode ser um exemplo interessante nesse sentido. Não há aqui uma concordância sobre qual seria a melhor agricultura, se a familiar ou o agronegócio. Um dos principais argumentos dos defensores do Fome Zero, o qual veremos na próxima seção, diz respeito justamente ao incentivo da agricultura local e familiar por parte do governo federal, uma vez que esta pode aumentar o desenvolvimento econômico de regiões pobres e assistidas pelo PFZ. Tal argumento está praticamente ausente nas falas dos deputados contrários ao Programa. Para tais parlamentares, desenvolver a agricultura com vistas ao combate à fome no Brasil significa aumentar o crédito aos produtores, não importando necessariamente o tipo de cultura à qual cada um se dedica. Isso ocorre, pois se tem vagamente, no discurso oposicionista, uma noção de desenvolvimento integrado, a qual postula a ideia de que qualquer forma de desenvolvi- 
mento econômico ajudará no combate à fome. O pronunciamento do deputado Almeida de Jesus (PL-CE) ilustra bem esta forma de relacionar o desenvolvimento agrícola com o PFZ:

Temos o Programa Fome Zero. Como vamos diminuir a fome do povo, se o salário mínimo não compra duas cestas básicas? Como vamos colaborar com o Fome Zero se o produtor rural do interior do Ceará não vai ter condições de fazer sua colheita, já que não há investimento? Há apenas uma medida provisória do Governo que autoriza a prorrogação da dívida do trabalhador. Isso não basta para fazer investimento em plantio, preparo da terra e colheita da safra. [...] Sugerimos ao Governo que una o útil ao agradável, que não deixe para agir daqui a seis meses. Por que não aprovamos uma medida provisória que autorize crédito suplementar para financiar a agricultura, a fim de que o trabalhador rural colha sua soja? (Diário da Câmara dos Deputados, 02/04/2003, p. 11494-11495).

Além dos dois aspectos críticos acima descritos, quais sejam, a natureza assistencialista do Programa Fome Zero e a necessidade de desenvolver economicamente o país, os parlamentares opõem-se ao modus operandi do governo no que diz respeito à condução da política. Nesse ponto, os seguintes aspectos são levantados: a) falta de inclusão de municípios pobres; b) falta de envolvimento dos municípios; c) publicidade do Programa em demasia e; d) gastos excessivos em viagens, diárias e custos operacionais.

O primeiro ponto, ou seja, a falta de inclusão de municípios a serem abrangidos pelo Programa é referido pelos deputados como forma de criticar a sua execução, denotando uma possível falta de informação por parte dos agentes públicos. Neste particular, os parlamentares apoiam-se em dados de institutos de mensurações geográficas e humanas para sustentar essa possível falta de organização ou de planejamento governamental. Nesse sentido, o pronunciamento do deputado Cláudio Cajado (PFL-BA) é exemplar:

Sr. Presidente, encaminho a V. Exa. Requerimento de informação ao Ministro Extraordinário de Segurança Alimentar e Combate à Fome, José Graziano, quanto aos critérios adotados para a inclusão de Municípios no Programa Fome Zero. No Estado da Bahia, em particular, o Programa não levou em consideração o índice de desenvolvimento social (IDS), calculado pela Secretaria de Planejamento do Estado, muito menos os índices do IBGE e do IPEA, adotados pela ONU. Com base no IDS, o Município baiano de Boa Nova foi considerado o mais pobre do Estado; segundo os cálculos do IBGE e do IPEA, o Município de Itapicuru. Entretanto, nenhum deles está incluído no Programa Fome Zero (Diário da Câmara dos Deputados, 26/03/2003, p. 09852).

Outro argumento ligado à política de condução do Programa diz respeito a sua necessidade de municipalização, a exemplo de outros programas sociais então em curso. Independentemente se o PFZ efetivamente prevê ações descentralizadas aos municípios, houve críticas de parlamentares no sentido de que isso não tinha efeito. Por se tratar de um programa social, o Fome Zero era muito comparado a outros programas, sobretudo àqueles 
oriundos do governo anterior, em que havia experiência de descentralização na execução em nível municipal. Nesse sentido, parece haver um sentimento compartilhado entre políticos de esquerda e de direita de que políticas municipalistas têm mais eficácia na condução de programas sociais, assim como no controle do gasto público. Nesse sentido, a intervenção do deputado Gervásio Silva (PFL-SC) reflete essa posição e esse desejo em relação ao PFZ:

É elogiável o Programa Fome Zero, mas o Município precisa ser envolvido, ser o agente executor do Programa, como ocorre com outros programas sociais. Há programas que os Municípios são parceiros: saúde da família, bolsa escola, bolsa alimentação. Esses são programas de sucesso executados pelos Municípios (Diário da Câmara dos Deputados, 11/ 03/2003, p. 05706).

O próximo ponto de crítica com relação à execução do PFZ diz respeito a sua publicidade entendida como em demasia. É sabido que o Programa teve grande campanha publicitária promovida pelo governo federal. É igualmente conhecido o fato de que o programa também foi uma das principais ações governamentais discutidas ao longo do primeiro semestre de 2003, período que abrange a análise de nosso corpus discursivo. Houve, por parte do governo, uma tentativa de envolver a sociedade civil no Programa e, neste particular, foi necessária a realização de campanha publicitária. Por parte da oposição, houve uma tentativa de desqualificá-lo, além dos argumentos acima expostos, também a partir da crítica ao excessivo gasto em publicidade e um correspondente "baixo" índice de ações concretas que minimizassem efetivamente a fome (mesmo que o curto período de existência do Programa não pudesse ser capaz de mensurar resultados de suas medidas). ${ }^{11}$ Nesse sentido, o deputado Cláudio Cajado (PFL-BA) enuncia:

Num momento em que o País se vê envolvido pela enorme campanha publicitária promovida pelo Governo Federal em cima do Programa Fome Zero, o que se espera é uma entrega integral por parte deste, paraque possamos vislumbrar resultados mais eficazes [...] (Diário da Câmara dos Deputados, 31/05/2003, p. 24234).

O último ponto referente às críticas com relação ao modus operandi do PFZ refere-se aos supostos gastos excessivos com viagens, diárias e demais custos operacionais referentes à implementação desta política. Neste ponto, apesar da necessidade prévia de geração de uma infraestrutura por parte do poder público - para após este efetivar concretamente uma determinada política, ainda mais em se tratando de um projeto da dimensão do PFZ - isso não é levado em consideração por parte de seus opositores. O ponto de crítica,

\footnotetext{
${ }^{11}$ A questão da intensa publicidade em relação ao PFZ e suas consequências, em parte negativas, foram também percebidas pela base de sustentação do governo. É o caso do pronunciamento do deputado federal Pedro Fernandes (PTB-MA): "não pode acontecer com as reformas o que aconteceu com o Programa Fome Zero: as ações de mídia e propaganda antecederam a elaboração e as medidas efetivas. Deu no que deu: uma excelente idéia foi exposta à corrosão das críticas, algumas delas, convenhamos, verdadeiras (Diário da Câmara dos Deputados, 29/04/2003, p. 17186).
} 
neste particular, diz respeito justamente aos pretensos gastos vultosos, mesmo sem se saber exatamente se eles assim o são. Esta é uma crítica de tipo conjuntural, no sentido de que se espera a ocorrência de um fato para que o programa possa ser significado de forma negativa, buscando-se, assim, minar o geral pelo particular, não importando, em absoluto, se $o$ atribuído fato negativo tenha efetivamente conotação criminosa, imoral etc. O objetivo final é reduzir a importância do Programa Fome Zero, diminuindo a credibilidade de seus gestores, como podemos perceber na passagem abaixo no pronunciamento do deputado Eduardo Cunha (PPB-RJ):

Ficamos curiosos para saber o que faz a Ministra da Assistência e Promoção Social em Paris, Bruxelas, Milão etc. Será que foi buscar alguma doação para o Programa Fome Zero? Aliás, esse programa já consumiu mais recursos com promoções, viagens e custos do que com as famílias carentes. Longe de queremos criticá-lo, mas sugerimos ao Governo um pouco mais de agilidade e de competência no gerenciamento (Diário da Câmara dos Deputados, 29/04/2003, p. 17158).

Assim, a partir da análise acima, podemos perceber que o principal argumento produzido no discurso dos deputados contrários ao PFZ foi efetivamente a acusação de que o mesmo seria de cunho meramente assistencialista e que seria necessária uma política mais ampla de desenvolvimento econômico para, aí sim, atacar efetivamente o problema da fome no país. O que ocorre é que esta política mais ampla, requerida pelos contrários do Programa, consiste justamente no principal argumento de seus defensores, o que será tratado na próxima seção deste artigo.

\section{O DISCURSO FAVORÁVEL AO PROGRAMA FOME ZERO}

Nesta seção, iremos apresentar o discurso e os recursos retóricos dos deputados favoráveis ao Programa Fome Zero. ${ }^{12}$ Assim, o principal argumento dos defensores do Programa grosso modo reside justamente na negação do seu caráter meramente assistencialista. Os parlamentares que defendem o PFZ argumentam que o mesmo tem um caráter estrutural, ou seja, para que a fome possa efetivamente ser erradicada no Brasil, é necessário um amplo esforço no sentido do desenvolvimento econômico do país.

Em linhas gerais, os defensores do Programa significam-no a partir de duas ações necessárias que devem ser implementadas conjuntamente. Nesse sentido, por um lado, é preciso que sejam tomadas medidas emergenciais com relação ao combate à fome. Por outro lado, são necessárias ações estruturais, no sentido de impulsionar o desenvolvimento econômico, sobretudo, aquele relacionado às comunidades diretamente afetadas pelo mal da fome e de outras necessidades relativas à miséria.

\footnotetext{
${ }^{12}$ Neste ponto, é interessante referirmos novamente a impossibilidade de fazermos uma análise dos discursos dos parlamentares estabelecendo como corte antagônico a questão partidária, o que sugeriria, portanto, que os membros dos partidos mantivessem uma exata coerência com relação a todas as posições políticas assumidas pela sigla. Neste sentido, por exemplo, contrariamente à posição majoritária dos parlamentares do PFL, o deputado Milton Barbosa (PFL-BA) assim manifestou-se com relação ao PFZ: "[...] devemos apoiar o Programa Fome Zero, ou qualquer sucedâneo seu, inclusive um programa único de transferência de renda, ainda que façamos as críticas necessárias e propostas que corrijam sua organização" (Diário da Câmara dos Deputados, 16/04/2003, p. 15079).
} 
Pensar o PFZ a partir dessas duas ações integradas já se constitui numa resposta à principal crítica oriunda dos seus adversários, ou seja, a de que o Fome Zero não passa de um programa assistencialista. Nesse exato ponto, é travada uma importante batalha discursiva entre os sentidos que buscam se hegemonizar a partir dos discursos em disputa. Assim, temos claramente a distinção entre duas noções acerca do Programa: ou esse é meramente "assistencialista" ou ele tem um necessário caráter "emergencial" inserido num plano de longo prazo. Sobre o primeiro, já tratamos na seção anterior e, desta forma, não cabe aqui retomar.

Já com relação ao sentido "emergencial", os defensores do Programa entendem que ele é necessário, devido à urgência das ações para o combate da fome e da pobreza. Contudo, argumentam que tais ações não são suficientes, uma vez que se somente ficasse na simples entrega de alimento às pessoas carentes, não haveria distinção alguma entre o PFZ e as já conhecidas práticas assistencialistas promovidas pelo Estado brasileiro há décadas, as quais nunca tiveram a real intenção de promover uma política efetiva de distribuição e de reconhecimento.

Entretanto, a natureza meramente assistencialista não está completamente ausente dos pronunciamentos dos deputados defensores do Programa. Mesmo não sendo comum entre os parlamentares, há aqueles que, mesmo defendendo o PFZ, o significam como assistencialista, como é possível perceber a partir do pronunciamento do deputado João Caldas (PL-AL):

O programa de combate à fome é positivo e oportuno. Lula empunha essa bandeira tardiamente, mas é necessário fazê-lo. Só agora ele se elegeu presidente da República, portanto, só agora pode defender essa bandeira no seio da nossa sociedade. (Diário da Câmara dos Deputados, 18/03/2003, p. 07452).

Nesta primeira parte do pronunciamento, o parlamentar avalia como "positivo e oportuno" o PFZ. Acrescenta ainda que o programa só está sendo implementado justamente por Lula ser o presidente da República, pois já deveria ter sido feito por governos anteriores. Até esse ponto, o deputado faz somente elogios ao Programa sem, contudo, apresentar, sua própria ideia acerca desta política pública, a qual aparece na sequência do pronunciamento:

Zequinha Cabeção, do distrito de Canastra, onde nasci, disse-me: 'Deputado, já me sinto de barriga cheia, porque Lula se lembra de nós'. Nessas palavras simples, percebemos que o povo tem esperança no Governo, tem esperança de ser olhado como pessoa e não como mendigo ou como quem vive dando trabalho à sociedade (Diário da Câmara dos Deputados, 18/03/2003, p. 07451).

Mesmo utilizando palavras de um membro de sua comunidade natal, o parlamentar deixa evidente sua posição com relação ao Programa: tem o objetivo único de matar a fome, de ser um programa de assistência social no nível mais básico, sem um compromisso necessariamente com inclusão social e desenvolvimento econômico. Aqui, portanto, não 
há uma clara diferença entre o que estabelece a fronteira antagônica dos prós e dos contrários ao PFZ, respectivamente os sentidos "emergencial" e "assistencialista". É digna de nota, também, a passagem "povo tem esperança no Governo, tem esperança de ser olhado como pessoa e não como mendigo", uma vez que denota uma hierarquização entre "pessoa" e os que estão abaixo da condição de pessoas, os "mendigos". Tal passagem aparece como um lapso discursivo do parlamentar.

Acima dissemos que o Programa Fome Zero tem como ações importantes àquelas que combatam emergencialmente a fome. Cabe-nos, agora, passar a um ponto que está, segundo seus defensores, presente nas intenções governamentais, ou seja, o Programa deve servir também como um meio de retirar definitivamente seus assistidos da condição de pobreza. Com relação a esse segundo ponto, seus defensores argumentam que o Fome Zero visa a atingir todas as fragilidades estruturais de seus assistidos. É a partir deste conceito que esta política pública tem a necessidade de enfrentar questões de natureza estrutural. Esta noção é bem traduzida na manifestação do deputado Francisco Gonçalves, do PTB-MG:

[...] está clara a idéia de que o Fome Zero não se reduz a um programa meramente emergencial ou apenas assistencialista, como se pode supor inadvertidamente. Trata-se, isto sim, de um grande projeto a médio e longo prazos, para reverter a triste e inaceitável situação de fome por que passam milhões de cidadãos brasileiros num Brasil tão farto. 0 elemento emergencial existe, sim, mas é apenas um foco da questão e não o mais importante (Diário da Câmara dos Deputados, 25/02/2003, p. 04014).

A partir desta ideia de ser um programa com ações e objetivos a médio e longo prazos, uma série de medidas são propostas. Iniciaremos com a questão da agricultura, a partir da qual se apresenta um novo ponto de diferenciação discursiva marcante entre as posições antagônicas em análise. Desta forma, vimos, na seção anterior, que os parlamentares contrários ao Programa defendiam que uma das saídas para a questão da fome no Brasil era a ampliação da agricultura no país, não importando necessariamente a forma como isso deveria ocorrer, tampouco os tipos de culturas que deveriam ser privilegiadas. De maneira diversa, os deputados defensores do PFZ entendem, majoritariamente, que o tipo de agricultura que melhor se aplica à referida política é a agricultura familiar. ${ }^{13}$ Nesse sentido, o deputado Francisco Gonçalves, no mesmo pronunciamento acima destacado, afirma: "vejo, assim, com satisfação, que o Presidente Lula, na sua mensagem ao Congresso Nacional, destacou o 'fortalecimento da agricultura familiar' como política estrutural no âmbito do Programa Fome Zero" (Diário da Câmara dos Deputados, p. 04015).

\footnotetext{
${ }^{13} \mathrm{Na}$ questão do tipo de agricultura que melhor se aplica ao PFZ, há ainda aqueles que veem a necessidade do fortalecimento do agronegócio, como o deputado Lincoln Portela (PL-MG), resgatando as palavras do então ministro da Agricultura: "a importância do apoio ao setor por parte do Governo fica ainda mais evidenciada na recente declaração do Ministro da Agricultura, Pecuária e Abastecimento, que assim se manifestou: 'O Governo terá sucesso no Programa Fome Zero na medida em que houver um compromisso da sociedade. Levarei para o seio do Governo a visão de agronegócio'" (Diário da Câmara dos Deputados, 08/04/2003, p. 13081).
} 
Outra proposta, também defendida pelos parlamentares, é a da integração do Fome Zero com os demais programas sociais já existentes, sendo o PFZ aquele de caráter mais geral. Assim, ações governamentais nas áreas de saúde e de educação, por exemplo, estariam também articuladas com o objetivo principal do Programa, no sentido de maior inclusão social de populações carentes. Neste ponto, é interessante destacar parte do pronunciamento do deputado Heleno Silva (PL-SE):

$\mathrm{O}$ atuante e criativo Ministro Cristovam Buarque, ele próprio o criador do Programa Merenda Escolar quando governador do Distrito Federal, já poderia determinar que fossem realizados estudos para estabelecer a exigência de compra local dos produtos da merenda, a ampliação do Bolsa-Escola, como formas integradas de combater à fome e ao analfabetismo e de geração de emprego e renda (Diário da Câmara dos Deputados, 16/04/2003, p. 15062).

Existe, na manifestação acima, a ideia da integração dos programas sociais existentes, ${ }^{14}$ além do fortalecimento da agricultura familiar, no sentido de que esta possa fornecer pelo menos parte da alimentação referente ao Programa Bolsa-Escola, subsidiando os pequenos agricultores, apoiando e desenvolvendo, em última análise, a economia local, fazendo com que os recursos investidos, na compra dos alimentos para as crianças, permanecessem na própria região que os produziu. Isso dependeria de uma decisão política do governo, no sentido de forçar determinadas ações por parte dos agentes públicos que diretamente operam, por exemplo, o Bolsa-Escola: a obrigatoriedade, quando possível, da compra de alimentos dos próprios produtores da região.

Os deputados ainda utilizam, como forma de sustentar a importância do Programa, a repercussão internacional que esse programa provocou no primeiro semestre de 2003. Assim, em vários momentos, sinalizações positivas, por parte de lideranças mundiais, são recuperadas nos pronunciamentos parlamentares. $O$ ponto que parece importante ser aqui destacado diz respeito ao argumento de que "se o mundo está olhando com bons olhos a ação do governo é porque o Programa realmente é positivo". A primeira manifestação neste sentido é a do deputado João Caldas (PL-AL):

Sr. Presidente, Lula comemora o discurso feito hoje em Roma pelo secretário-geral da ONU, Koffi Annam, que afirma que o combate à fome e à miséria é a grande prioridade mundial. Por intermédio do porta-voz da Presidência, André Singer, o presidente Lula disse que as palavras de Annam revelam que 'o mundo está mudando para melhor' e confessou estar orgulhoso em saber que a questão considerada prioritária por seu Governo conta com o apoio decisivo da ONU (Diário da Câmara dos Deputados, 21/02/2003, p. 03585).

\footnotetext{
${ }^{14}$ Outro exemplo de manifestação favorável à integração das políticas sociais já existentes pode ser claramente percebido na manifestação do deputado João Caldas, do PL-AL: "a Frente Parlamentar também está trabalhando para que ao programa Fome Zero se engajem todos os outros programas sociais do Governo - proposta do Ministro da Educação, Cristovam Buarque - como o de erradicação do analfabetismo, por exemplo, uma forma de acabar com a miséria, a pobreza, porque sem oferecer educação ao povo não iremos a lugar nenhum" (Diário da Câmara dos Deputados, 13/03/2003, p. 06334).
} 
A referida manifestação do secretário-geral da ONU pode ser entendida como um importante recurso retórico no sentido de, primeiramente, avalizar a importância de uma política de combate à fome. Mais do que simplesmente sinalizar a importância do mérito do Programa, o que seria dispensável o recurso às palavras de Annam, sua manifestação é aqui usada para avalizar também a credibilidade do mesmo. Assim, a palavra do estrangeiro, do "secretário-geral da ONU" é utilizada para reforçar a ideia de que o Programa Fome Zero, como política pública do governo federal, deve ser aplaudido e levado adiante, uma vez que se trata de uma política séria. Reforçando a ideia de uma política séria do governo, podemos passar às palavras do deputado Severino Cavalcanti, que fazem menção às reações de organismos financeiros internacionais ao PFZ:

Sr. Presidente, as reações dos organismos internacionais ao anúncio do Fome Zero, ao contrário das críticas internas e muitas vezes injustas, têm sido animadoras. Dirigentes de organismos internacionais como o Banco Mundial e o Banco Interamericano de Desenvolvimento não só têm declarado apoio à idéia como também têm acenado com o incremento de recursos para a implementação (Diário da Câmara dos Deputados, 18/03/2003, p. 07423).

De acordo com a manifestação de Cavalcanti, o PFZ tem sofrido uma série de "críticas internas e muitas vezes injustas", contrastando com o apoio de organismos internacionais. Chama à atenção, neste ponto, a intenção do parlamentar de descaracterizar as críticas "internas", pelo argumento do apoio "externo". Nesse sentido, quando o parlamentar faz menção ao fato de que dois bancos internacionais, não-somente apoiam esta política pública como, inclusive, acenam com a possibilidade de aporte de recursos para a sua melhor implementação, isso significa, por um lado, que o Banco Mundial e o Banco Interamericano de Desenvolvimento acreditam no mérito, na importância do Programa e, por outro lado, acreditam também no próprio recém-empossado governo brasileiro, mesmo este estando alinhado a um campo mais à esquerda, uma vez que veem a possibilidade de apoiá-lo com empréstimos de recursos financeiros.

Assim, pode-se sucintamente resumir que o principal argumento dos defensores do Programa Fome Zero reside na defesa de que o mesmo se trata de um plano de ações a curto, médio e longo prazos, no sentido da implementação de medidas emergenciais e estruturais. Dessa forma, todos os usos retóricos na defesa do PFZ sustentam-se nessa ideia-força: no fato de que o Programa tem o objetivo central de emancipar as populações que sofrem do mal da fome e da miséria e, para tanto, suas ações têm de ser estruturais em última análise.

\section{APRESENTANDO UMA HIPÓTESE PARA ANÁLISE}

Neste trabalho, tratamos da disputa discursiva acerca dos sentidos produzidos em relação ao Fome Zero. Pelo lado dos deputados contrários ao Programa, temos como principal argumento o registro de que esse programa seria tão-somente uma medida política assistencialista. Já pelo lado daqueles parlamentares defensores do PFZ, temos como prin- 
cipal recurso argumentativo o fato de que o programa se trata, na verdade, de uma política pública mais ampla e estrutural, com o fito de retirar, de forma permanente, seus assistidos da situação de pobreza.

Essas construções discursivas antagônicas foram identificadas a partir da análise stricto sensu dos pronunciamentos parlamentares nas sessões do Grande Expediente da Câmara Federal. Para além desta conclusão, queremos propor uma hipótese adicional, a qual norteará nossos futuros trabalhos sobre o comportamento dos partidos de direita no primeiro mandato do governo Lula, sobretudo, considerando aqueles deputados que se colocam contrariamente à política implementada por este governo.

Nossa hipótese, portanto, consiste na afirmação de que não há argumentos, propostas e/ou políticas que tenham necessariamente um locus ou no campo da esquerda ou no campo da direita. Sustentamos, no contexto político contemporâneo brasileiro, contrariamente a essa divisão ideológica tradicional, que existem, na verdade, argumentos e/ou propostas políticas típicas de um comportamento de oposição em relação a uma dada situação governativa.

Um exemplo, oriundo de uma parlamentar do PFL, contrária ao Programa Fome Zero, pode ser bem ilustrativo para apoiar nosso argumento. Nesse sentido, afirma a deputada Nice Lobão do PFL-MA:

Ora, Sr. Presidente, o Fome Zero está patinando há 5 meses, gastando uma fábula em viagens e diárias com os funcionários responsáveis pela sua implementação, sem resultados concretos até o presente momento.

Enquanto isso, a fome no Brasil continua; o desemprego alcança índices alarmantes; a economia brasileira encolhe; os compromissos com o FMI ultrapassam as expectativas de superávit primário; os juros são mantidos na estratosfera; e, para completar, o Governo vai gastar alguns miIhões com a convocação extraordinária do Congresso para sacrificar os nossos velhinhos com a absurda taxação de suas aposentadorias.

Soa como piada de mau gosto pedir doação aos Deputados para o Programa Fome Zero!

Basta ao Governo, se quiser seriedade com o assunto, reduzir o religioso pagamento de juros da dívida externa e canalizar esses recursos para reduzir o desemprego e a Fome no País (Diário da Câmara dos Deputados, 05/06/2003, p. 25446).

No excerto acima, a parlamentar apresenta suas críticas ao Programa Fome Zero, inicialmente apontando a ineficácia do governo com relação aos aspectos administrativos de sua implementação, argumento já discutido acima. A partir daí, elenca uma série de argumentos já utilizados, por exemplo, por parlamentares petistas quando estavam na oposição que merecem ser destacados: 1) alto índice de desemprego; 2) economia "encolhida"; 3) manutenção de compromissos com o FMI; 4) juros altos e; 5) gastos com a convocação extraordinária do Congresso Nacional para votar medida com efeitos contrários aos direitos dos aposentados. Além disso, a deputada do PFL conclui sua manifestação com uma frase que comumente seria atribuída a um parlamentar ou político vinculado a um partido de esquerda: "Basta ao Governo, se quiser seriedade com o assunto, reduzir o 
religioso pagamento de juros da dívida externa e canalizar esses recursos para reduzir o desemprego e a Fome no País". Talvez a única ressalva no que diz respeito a esta última afirmação da parlamentar seja a palavra "reduzir". Possivelmente um político de esquerda a substituiria por "cancelar" ou "parar". Contudo, o restante do excerto poderia ser atribuído a um parlamentar do PT, por exemplo, quando este figurava na oposição.

Poder-se-ia argumentar que o que a deputada disse não passou de um simples recurso retórico, que sua fala não faz parte necessariamente de sua ideologia política, do discurso efetivo de seu partido. Mas problematizando este argumento, perguntamos: quem garante que o que a esquerda fazia quando mencionava tais questões - quando frentes de centro-direita estavam no poder - não era também de mero efeito retórico?

Com isso queremos dizer que não existe, no contexto contemporâneo da política brasileira, necessariamente um discurso de direita e um discurso de esquerda, mas discursos típicos de oposição. O que nos acostumamos a entender como um discurso de esquerda e, algumas vezes, fixá-lo como sendo restritamente de esquerda, deveu-se ao fato de que a esquerda teve somente agora chance de ser governo, de sair do campo da oposição. 0 exercício crítico da oposição não tem necessariamente de ser responsável; basta que ele seja contrário.

No caso específico do Programa Fome Zero, parece claro, não haveria condições discursivas de se argumentar contra o combate à fome, pois isso, além de ser politicamente inviável, seria um ato de profunda desumanidade. Assim, como já vimos, a estratégia dos parlamentares contrários restingiu-se a dois pontos básicos. Um tem relação com a retórica da ineficácia da implementação do Programa. O outro, e mais importante, tem a ver com a afirmação de que o mesmo é tão-somente assistencialista. Sabemos da insegurança de se fazer análises a partir de meras situações hipotéticas, mas seria estranho pensar que as críticas dos parlamentares de esquerda não seria neste exato sentido, caso estivessem esses na oposição? Se a política tivesse sido implementada pelo presidente Fernando Henrique Cardoso, seria um absurdo pensar que um deputado do PT poderia dizer que o mesmo Programa seria assistencialista, com fins meramente eleitoreiros? É tal hipótese, muito sucintamente aqui desenvolvida, que procuraremos testar em trabalhos posteriores.

\section{REFERÊNCIAS BIBLIOGRÁFICAS}

ANANIAS, Patrus. Fome Zero. Ministério do Desenvolvimento Social e Combate à Fome, 2004. Disponível em: <http://www.mds.gov.br/noticias_antigas/noticia473.htm/html2pdf>. Acesso em: 26 jul. 2008.

BELIK, Walter; DEL GROSSI, Mauro. O programa fome zero no contexto das políticas sociais no Brasil. Fome Zero, 2003. Disponível em: <http://www.fomezero.gov.br/download/O Fome Zero no contexto>. Acesso em: 26 jul. 2003.

BRASIL. Diário da Câmara dos Deputados. Jan./jul. 2003.

FOUCAULT, Michel. A arqueologia do saber. 5. ed. Rio de Janeiro: Forense Universitária, 1997. 
LACLAU, Ernesto; MOUFFE, Chantal. Hegemony and socialist strategy: towards a radical democratic politics. London: Verso, 1985.

MAINWARING, Scott; MENEGUELLO, Rachel; POWER, Timoty. Partidos conservadores no Brasil contemporâneo: quais são, o que defendem, quais são suas bases. São Paulo: Paz e Terra, 2000.

RODRIGUES, Leôncio Martins. Partidos, ideologia e composição social: um estudo das bancadas partidárias na Câmara dos Deputados. São Paulo, EdUSP, 2002a. fev. 2002b.

Partidos, ideologia e composição social. Revista Brasileira de Ciências Sociais, v.17, n. 48, p. 31-47,

SILVA, José Graziano da; BELIK, Walter; TAKAGI, Maya. Para os críticos do Fome Zero. Fome Zero, 2001. Disponível em: <http://www.fomezero.gov.br/download/50fomezero2.pdf>. Acesso em: 26 jul. 2008.

YASBEK, Maria Carmelita. O programa fome zero no contexto das políticas sociais brasileiras. São Paulo em Perspectiva, v. 18, n. 2, p. 104-112, 2004. 